В вопросах помощи безработному населению приоритет должен быть отдан расширению полномочий органов муниципальной власти в сфере реализации государственной политики управления занятостью.

Реализация указанных направлений будет способствовать постепенному сглаживанию диспропорций между структурой рабочих мест в экономике региона и профессиональным составом трудовых ресурсов [1].

Переход к инновационной экономике и развитие информационного общества требуют переосмысления подходов к политике регулирования рынка труда. Ключевым звеном должно стать обеспечение повышения потенциала развития рынка труда. Потенциал развития рынка труда можно рассматривать как трудовой потенциал региона, то есть как способность населения участвовать в общественном производстве. Регулирование рынка труда на региональном уровне требует разработки механизмов, обеспечивающих повышение потенциала развития рынка труда [2]. Потенциал развития рынка труда можно рассматривать как трудовой потенциал региона, то есть как способность населения участвовать в общественном производстве. Трудовой потенциал с его количественными и качественными характеристиками становится основой для перехода к инновационной экономике и развития информационного общества.

Все перечисленные меры при их кажущейся простоте - это инструменты, которые должны применяться правильно. Они в состоянии как сыграть положительную роль в решении проблемы безработицы, так и отрицательную (такое возможно в случае провала государственной политики, что отнюдь не является редкостью в мировой практике). Тем более, что и сама занятость - это не только активность рынка труда, не только объемы приложения труда, но и эффективность его использования и качество труда.

$$
* * *
$$

1. Деневизюк Д.А. Анализ ситуации и меры реализации политики занятости в регионе / Журнал: Региональные проблемы преобразования экономики. - № 8 (82), 2017. - С. 64-72.

2. Исраилов М.В. Формирование государственной политики регулирования рынка труда на региональном уровне / Журнал: Вестник Чеченского государственного университета. - Том: 38, № 2, 2020. - C.26-31.

3. Колесникова О.А. О некоторых подходах к оценке и достижению эффективной занятости / Журнал: Международный научный вестник (Вестник объединения православных ученых). - № 4 (8), 2015. - С. 30-32.

4. Путин В. Заведомо невыполнимые социальные обязательства государства - тяжелый недуг, от которого мы постепенно излечиваемся //Человек и труд. - 2002. - № 1. - C.5.

5. Серебрякова Н.А., Агафонов С.М. Политика регулирования рынка труда в регионе: сущность и содержание // Вестник ВГУИТ. 2018. №2 (76). - С.424-430.

\title{
Саралинова Д.С.
}

\section{Значение аттестации государственных и муниципальных служащих}

ФГБОУ ВО «Чеченский государственный университет» (Россия, Грозньй)

doi: $10.18411 / 1 j-10-2020-82$

idsp: ljournal-10-2020-82

\section{Аннотация}

Актуальность данной темы состоит в анализе одного из наиболее значимых элементов прохождения службы - аттестации государственных и муниципальных служащих. С помощью системы аттестации проводится оценка уровня соответствия знаний, умений, навыков и квалификации служащих муниципальных органов управления занимаемым им должностям. Вследствие чего крайне важно, чтобы 
порядок проведения аттестации был эффективным и предоставлял возможность объективно оценивать профессиональные навыки сотрудников, к тому же, в соответствие с результатами аттестации принимаются решения о сокращении, перемещении или повышении служащего в должности.

Ключевые слова: государственная служба, муниципальная служба, аттестация, кадровая работа.

\section{Abstract}

The relevance of this topic lies in the analysis of one of the most significant elements of service - the certification of state and municipal employees. With the help of the certification system, the level of conformity of knowledge, skills, abilities and qualifications of employees of municipal government bodies to their positions is assessed. As a result, it is extremely important that the certification procedure is effective and provides an opportunity to objectively assess the professional skills of employees, moreover, in accordance with the certification results, decisions are made on the reduction, transfer or promotion of an employee in position.

Keywords: public service, municipal service, certification, personnel work.

Концептуальная модель сегодняшнего государственного и муниципального служащего нацелена на соответствие требуемых сегодняшним днем профильных знаний, умений, навыков и существующих задач в специфических условиях хозяйствования и экономической ситуации [4].

Аттестация государственного и муниципального служащего в процессе прохождения службынеобходима для определения уровня профессиональной подготовки служащего и степени ее соответствия квалификационным требованиям, предъявляемым к должностям службы [3].

Проблема подготовки и переподготовки государственных и муниципальных служащих остается в ряду наиболее острых и актуальных в вопросах обеспечения и развития современной кадровой ситуации. Однако, основная проблема заключается в том, что процесс аттестации на государственной гражданской и муниципальной службе, как правило, носит чисто формальный характер, вследствие чего не имеет должной эффективности и объективности оценок деятельности аттестуемых государственных и муниципальных служащих.

Аттестация государственного и муниципального служащего необходима для исследования уровня профессионализма, образованности и компетентности служащего в процессе выполнения им своих должностных обязанностей. Поэтому очень важна ее результативность и эффективность.

Анализ научной литературы свидетельствует о том, что теоретическое осмысление проблемы эффективности такого инструмента оценки персонала как аттестация неисчерпаема, приращение знаний в этой области идет непрерывно.

Теоретические вопросы и проблемы аттестации государственных служащих рассматриваются в работах Л.В. Басиевой, И.И. Севостьянова, К.С.Жуковой, Е.К. Карпунина, А.В. Катункиной, А.Я. Кибанова, В.Ю. Корнюшина, А.И. Лагунова и других. В.С. Бялт, Д.И. Богачука, В.В. Зотова, А.Ю. Кочневой, С.С. Куликова, Е.И. Михайловой и т.д. И.А. Абрамов анализирует процедуру аттестации государственных гражданских служащих РФ, а В.С. Бялт и Д.И Багачук выделяют особенности аттестации сотрудников внутренних дел. Д.Р. Мокин описывает процедуры, правовое регулирование и особенности практики проведения аттестации. Зотов В.В. и Кузнецова M.В. описывают диагностику процедуры аттестации для профессиональной самореализации на государственной и муниципальной службе. И это только некоторые исследования. 
Аттестация - это неукоснительная процедура для любого служащего. Аттестация имеет важное значение в практической деятельности служащих. Она является правовым средством расширения демократических начал в кадровой политике государства. Также она выступает средством обеспечения формирования и реализации целенаправленной и предсказуемой кадровой политики в деле формирования персонала управления в этих органах [5].

Аттестация персонала - это важный организационный инструмент кадровой работы, представленный совокупностью форм и методов работы, посредством которых должно обеспечивается поддержание уровня их квалификации прогрессивным требованиям и нормам функционирования организации. Значение аттестации в современных условиях возрастает, так как благодаря ей реализуются вопросы адаптации индивида к внешним условиям, учета личностного фактора в построении системы управления персоналом организации. Грамотно поставленная система аттестации персонала позволяет решить сразу две сложнейших и важных задачи: оптимизировать расходы на заработную плату, а также значительно повысить мотивацию персонала [2].

Аттестация персонала позволяет каждому руководителю знать, насколько эффективно работают его сотрудники. Она является базовой процедурой, необходимой для эффективного управления компанией. Общими словами можно сказать, что аттестация персонала является мероприятием, целью которого является определить, в какой степени сотрудники соответствуют занимаемым должностям.

Для того, чтобы направить мотивацию персонала в нужное русло, в организации составляется программа обучения и развития персонала. Выявить способности и возможности отдельного работника, определить, насколько он справляется с возложенными на него обязанностями, насколько сильна заинтересованность конкретной личности, как в собственном профессиональном развитии, так и в качественном достижении целей организации - все это можно понять только благодаря проверке.

Регулярно проводимая аттестация позволяет проводить проверку совместимости работника с коллективом (умение работать в команде, лояльность организации, работодателю и руководству), мотивации к труду, к работе в данной должности и определять перспективы развития карьеры данного работника [1].

Аттестационные мероприятия органично взаимно увязываются с кадровой работой в организации, и результаты аттестации являются основой укрепления трудовой дисциплины и повышения эффективности кадровой работы. Также благодаря аттестации выявляются должности или функции, дублирующие или «пустые» и происходит их сокращение или реорганизация.

Следует отметить недостаточную подготовленность большинства служащих к работе в области государственного и местного самоуправления, так как основной контингент - это «старые» работники, работавшие еще в советские времена. Кадры, пришедшие на госслужбу в эпоху перемен, также нуждаются в серьезной профессиональной подготовке и переподготовке [4], так как в то нелегкое время руководящие должности на государственной службе занимали лица, не имеющие специальной подготовки, а иногда, даже мало представляющие специфику нового для российской действительности вида службы. В основном, те лица имели отраслевое образование, в лучшем случае, опыт работы на руководящих должностях, а о специальной подготовке к управленческой деятельности вообще имели слабое представление. Молодежь более подготовлена теоретически, но еще недостаточно опытна, поэтому изменения качественной структуры кадров государственной и муниципальной службы происходят очень медленно. 
Современные условия развития требуют оптимального использования человеческих и финансовых ресурсов на местах. Систематическое изучение и анализ квалификации государственных/муниципальных служащих проводится в целях определения степени их подготовленности к замещению вышестоящей должности, а также корректировки планов их подготовки.

Организационная структура и состав кадров оказывают огромное влияние на эффективность работы органа государственной или муниципальной власти. Поэтому необходимо проводить анализ влияния структуры и состава кадров на производительность и эффективные результаты деятельности организации. Равным образом, сложившаяся структура организации требует анализа существенных финансовых и административных условий. $\mathrm{C}$ другой стороны, постоянный количественный рост и сфера активности персонала требуют определения и уточнения позиций, занимаемых участниками процесса аттестации в отношении поставленных задач. При этом, лишь новая модель организационной деятельности будет способствовать подготовке и реализации дальнейших направлений развития механизма аттестации служащих.

Совершенствование системы аттестации государственных и муниципальных служащих может осуществляться по нескольким направлениям. Первым и наиважнейшим является совершенствование законодательной и нормативно-правовой базы процедур аттестации в органе власти. На сегодняшний день непроработанность вопросов проведения аттестации является основной проблемой регулирования государственной и муниципальной службы в РФ. Это требует совершенствования с нормативно-правовой точки зрения.

Крайне важно, чтобы порядок проведения аттестации был эффективным и предоставлял возможность объективно оценивать профессиональные навыки сотрудников, ведь в соответствии с результатами аттестации принимаются решения о сокращении, перемещении или повышении служащего в должности.

Основным направлением решения проблем аттестации муниципальных служащих является заимствование эффективных инструментов процесса аттестации в системе государственной гражданской службы. Так, представляется целесообразным закрепление типового порядка проведения аттестации на муниципальной службе по аналогии с государственной гражданской службой. Унификация процедуры аттестации в данной сфере также определит дополнительные точки взаимосвязи и соотносимости государственной и муниципальной службы.

Еще один действенный инструмент - это развитие и закрепление в качестве одной из основных такой формы аттестации как собеседование, посредством которого аттестационная комиссия имеет возможность получить об аттестуемом не только набор сведений и характеристик деятельности, но представление о нем как о личности, профессионале, гражданине.

$$
* * *
$$

1. Алтухова К.В., Реутова Ю.И. Мотивация и стимулирование трудовой деятельности муниципальных служащих / Журнал: Аллея науки. - Том: 3, № 1 (28), 2019. - С. 563-566.

2. Зотов В.В., Кузнецова М.В. Диагностика процедуры аттестации для профессиональной самореализации на государственной гражданской службе // Вестник ПАГС. 2014. №2 (41). - С.1720.

3. Лужбина Т.А. Правовое регулирование работы с кадрами в органах власти: проблемы и пути совершенствования / Журнал: Молодой ученый. - № 22 (312), 2020. - С. 272-274.

4. Саралинова Д.С. Кадровый потенциал как основа функционирования и развития аппарата муниципальной власти / Наука и бизнес: пути развития. 2018. № 11 (89). - С. 173-175.

5. Чиркова Ю.Р. Исторический опыт обучения и профессиональной подготовки государственных служащих в России и ведущих странах мира / Журнал: Духовная ситуация времени. Россия XXI век. - № 2 (17), 2019. - С.5-13. 